\title{
Glutathione S-transferases P1 protects breast cancer cell from adriamycin-induced cell death through promoting autophagy
}

\author{
Xiaoliang Dong ${ }^{1} \cdot$ Yang Yang ${ }^{1,4,5} \cdot \mathrm{Yi}_{\mathrm{Z}} \mathrm{hhou}^{2} \cdot$ Xiaowen $\mathrm{Bi}^{2} \cdot$ Ningwei Zhao ${ }^{3,7} \cdot$ Zhengping Zhang $^{1,6} \cdot \mathrm{Ling} \mathrm{Li}^{1} \cdot$

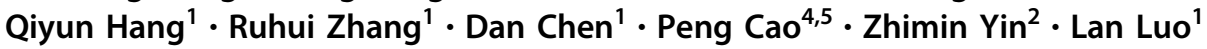

Received: 16 August 2018 / Revised: 19 December 2018 / Accepted: 20 December 2018 / Published online: 25 January 2019

(c) ADMC Associazione Differenziamento e Morte Cellulare 2019

\begin{abstract}
Glutathione S-transferases P1 (GSTP1) is a phase II detoxifying enzyme and increased expression of GSTP1 has been linked with acquired resistance to anti-cancer drugs. However, most anticancer drugs are not good substrates for GSTP1, suggesting that the contribution of GSTP1 to drug resistances might not be dependent on its capacity to detoxify chemicals or drugs. In the current study, we found a novel mechanism by which GSTP1 protects human breast cancer cells from adriamycin (ADR)-induced cell death and contributes to the drug resistance. GSTP1 protein level is very low in human breast cancer cell line MCF-7 but is high in ADR-resistant MCF-7/ADR cells. Under ADR treatment, MCF-7/ADR cells showed a higher autophagy level than MCF-7 cells. Overexpression of GSTP1 in MCF-7 cells by using the DNA transfection vector enhanced autophagy and down-regulation of GSTP1 through RNA interference in MCF-7/ADR cells decreased autophagy. When autophagy was prevented, GSTP1-induced ADR resistance reduced. We found that GSTP1 enhanced autophagy level in MCF-7 cells through interacting with $\mathrm{p} 110 \alpha$ subunit of phosphatidylinositol-3-kinase (PI3K) and then inhibited PI3K/protein kinase B (AKT)/mechanistic target of rapamycin (mTOR) activity. Proline123, leucine160, and glutamine163, which located in C terminal of GSTP1, are essential for GSTP1 to interact with p110 $\alpha$, and the following autophagy and drug resistance regulation. Taken together, our findings demonstrate that high level of GSTP1 maintains resistance of breast cancer cells to ADR through promoting autophagy. These new molecular insights provide an important contribution to our better understanding the effect of GSTP1 on the resistance of tumors to chemotherapy.
\end{abstract}

These authors contributed equally: Xiaoliang Dong, Yang Yang

Edited by E. Baehrecke

Supplementary information The online version of this article (https:// doi.org/10.1038/s41418-019-0276-y) contains supplementary material, which is available to authorized users.

$\triangle$ Lan Luo

lanluo@nju.edu.cn

$\triangle$ Zhimin Yin

yinzhimin@njnu.edu.cn

1 State Key Laboratory of Pharmaceutical Biotechnology, School of Life Sciences, Nanjing University, Nanjing 210023, China

2 Jiangsu Province Key Laboratory for Molecular and Medicine Biotechnology, College of Life Science, Nanjing Normal University, Nanjing 210046 Jiangsu, China

\section{Introduction}

Drug resistance remains the main obstacle to effective cancer therapies. The potency of both targeted therapy and nontargeted chemotherapy is limited by drug resistance [1]. Resistance to antitumor therapy can be classified by two categories including intrinsic and acquired [2].

3 Shimadzu Biomedical Research Laboratory, Shanghai 200233, China

4 Affiliated Hospital of Integrated Traditional Chinese and Western Medicine, Nanjing University of Chinese Medicine, Nanjing 210028, China

5 Laboratory of Cellular and Molecular Biology, Jiangsu Province Academy of Traditional Chinese Medicine, Nanjing 210028, China

6 Jiangsu Simovay Pharmaceutical Co., Ltd., Nanjing 210042, China

7 Laboratory of Pharmacology, Affiliated Hospital of Nanjing University of Chinese Medicine, Nanjing 210029, China 
Intrinsic resistance results from the factors that exist prior to receiving the intended therapy and acquired resistance develops during the course of treatment. Both intrinsic and acquired resistances have been observed in chemotherapy $[3,4]$.

The resistance to cancer chemotherapeutic drugs can be induced by altered activity of specific enzymes which decrease the cytotoxic activity of drugs in a manner independent of intracellular drug concentrations [5]. Among these enzymes, glutathione S-transferase P1 (GSTP1) is mainly responsible for drug resistance targeted at a wide range of chemotherapeutic agents. GSTP1 is an important isozyme of glutathione S-transferase (GST) family which is primarily known for their ability to catalyze the conjugation of the reduced form of glutathione to xenobiotic substrates for the purpose of detoxification [6-8]. Tumor cell lines overexpressed GSTP1 are found to be resistant to a variety of drugs [8,9]. Early reports demonstrated that GSTP1 inactivates chemotherapeutic substances by conjugating them to GSH [10, 11]. However, many anticancer compounds are not substrates of GSTP1, thus the reason for the high levels of GSTP1 are not always clear. MCF-7/ADR cells (a breast cancer cell line resistant to adriamycin) have $\sim 50$-fold more GSTP1 than the wild type MCF-7 cells which have very low GSTP1 levels [12]. Since GSH conjugates of ADR do not occur under physiological conditions, the relationship of GSTP1 and ADR resistance is not easily explained by GSTP1 catalytic properties [13]. Recent investigations have suggested that GSTP1 has a diversity of functions in cancer cells, some of which are unrelated to its capacity to detoxify chemicals or drugs [14]. GSTP1 appears to act as a non-catalytic ligand-binding protein to regulate cellular signal pathway $[15,16]$. Some reports suggest that the role of GSTs in the development of drug resistance might be due to the inhibition of the mitogen-activated protein (MAP) kinase pathway by protein-protein interactions $[17,18]$. But the mechanism by which GSTP1 protects cells against anticancer drugs remains equivocal.

Anti-cancer therapies, including the cytotoxic chemotherapy and pathway inhibitory therapy, can induce autophagy in most cancer cell lines [19, 20]. Autophagy is a cellular degradation process, which can be induced by different metabolic stresses and its pro-survival function has been demonstrated in various contexts including nutrient and growth factor deprivation, endoplasmic reticulum stress, development, hypoxia, and infection [21-23]. Cancer cells may have high bio-energetic demands and require more nutrients than normal cells. At advanced stages of tumor development, the induction of autophagy allows cancer cells to survive in the low-nutrient and low-oxygen conditions [24]. It has been reported that chemotherapeutic drugs, including topotecan, cyclophosphamide, temozolomide, and gemcitabine, could induce autophagy which protected cancer cells against anticancer treatments by blocking the apoptotic pathway [24-26]. In the occurrence and progression of gastric cancer, autophagy plays an important role especially during the development of resistance to chemotherapy $[27,28]$.

In this study, we demonstrate that GSTP1 promotes autophagy through interacting with the catalytic subunit of PI3K, p110 $\alpha$, and then preventing PI3K-Akt-mTOR pathway signaling. Our study indicates a novel mechanism by which GSTP1 induces drug resistance of cancer cells.

\section{Materials and methods}

\section{Cell culture and transfection}

Wild type MCF-7 cell line (Cat No. KG031) and the derived resistant cells (MCF-7/ADR) (Cat No. KG0311) were purchased from KeyGEN BioTECH, China. MCF-7 and MCF-7/ADR were maintained in MEM (Wisent, Canada) containing 10\% fetal bovine serum (FBS) (Gibco, USA), $100 \mathrm{IU} / \mathrm{mL}$ penicillin, and $10 \mathrm{mg} / \mathrm{mL}$ streptomycin (Wisent, Canada) at $37{ }^{\circ} \mathrm{C}$ in a humidified $5 \% \mathrm{CO}_{2}$ atmosphere. To maintain the resistance property, MCF-7/ADR cells were cultured in the presence of a low concentration of ADR $(1 \mu \mathrm{M})$ every 4 weeks. MDA-MB-468 cells (Cat No. HTB-132) were purchased from ATCC and were maintained in L15 Medium containing 10\% FBS (Gibco, USA), $100 \mathrm{IU} / \mathrm{mL}$ penicillin, and $10 \mathrm{mg} / \mathrm{mL}$ streptomycin (Wisent, Canada) at $37^{\circ} \mathrm{C}$ in $100 \%$ atmosphere. All the cell lines were kept within 10 passages and preserved in liquid $\mathrm{N}_{2}$ after receipt, and were authenticated using short tandem repeat profiling and confirmed to be free of mycoplasma prior to use.

MCF-7, MCF-7/ADR, or MDA-MB-468 cells were seeded into 12 -well plates $24 \mathrm{~h}$ prior to transfection at approximately $80 \%$ confluence. Transient transfection was performed using Lipofectamine ${ }^{\mathrm{TM}} 3000$ Transfection Reagent (Invitrogen, USA) according to the manufacturer's instructions. Briefly, Lipofectamine ${ }^{\mathrm{TM}} 3000$ was added to Opti-MEM $^{\mathrm{TM}}$ Medium (Gibco, USA) along with plasmid DNA and P3000 reagent and incubate for $15 \mathrm{~min}$. Finally, DNA-lipid complex was added to cells. In all cases, the total amount of DNA was normalized by the addition of empty control plasmids.

\section{MTT assay}

Cells were plated at 5000 cells/well in 96-well plates and incubated at $37^{\circ} \mathrm{C}, 5 \% \mathrm{CO}_{2}$ for $24 \mathrm{~h}$. After treatments, 3-(4, 5-dimethyl-2-thiazolyl)-2,5-diphenyl-2-H-tetrazoliumbromide (MTT, Sigma-Aldrich, USA) were added into medium at a 
final concentration of $0.5 \mathrm{mg} / \mathrm{mL}$ and incubated at $37^{\circ} \mathrm{C}$ for 4 h. Reduced MTT shown as a purple formazan was dissolved in dimethyl sulfoxide (DMSO, AMRESCO, USA) and detected at the wavelength of $490 \mathrm{~nm}$ with microplate reader (BIO-TEK, USA).

\section{Reagents and antibodies}

Anti-LC3B (\#2775s), anti-phospho-4E-BP1 (Thr $\left.{ }^{37 / 46}\right)$ (\#2855), anti-mTOR (\#2972), anti-phospho-mTOR (\#5536) antibodies were purchased from Cell Signaling Technology, USA. Anti-Akt (21054), anti-phospho-Akt (11054) antibodies were purchased from Signalway Antibody, USA. Anti-GSTP1 (BS7629), anti-GAPDH (AP0063), and Goat anti-Rabbit IgG (H\&L)-HRP (BS12478) antibodies were obtained from Bioworld, USA. GSTP1 antibody used for co-immunoprecipitation (ab53943) and anti-SQSTM1/p62 (ab91526) antibodies were purchased from Abcam, USA. Anti-Flag (20543-1-AP), anti-p110 $\alpha$ (21890-1-AP), antip85 $\alpha$ (60225-1-Ig), FITC-conjugated Affinipure Donkey Anti-Goat (SA00003-3), and Alexa Fluor 594-conjugated Goat anti-Rabbit (SA00006-4) secondary antibodies were purchased from Proteintech, USA. Goat anti-Mouse Alexa Fluor 555 Secondary Antibody (A-21424), Goat anti-Rabbit Alexa Fluor 488 Secondary Antibody (A-11034) were purchased from Thermo Fisher Scientific, USA.

\section{Plasmids}

pcDNA3.1-Flag-GSTP1 and pcDNA3.1-Flag-GSTP1(Y7F) (phenylalanine replaced tyrosine in the seventh aminoterminal position) were kept in our lab. pcDNA3.1-FlagGSTP1(P123D) (PRO123 was replaced by aspartic acid (ASP)), pcDNA3.1-Flag-GSTP1(P123K) (PRO123 was replaced by lysine (LYS)), pcDNA3.1-Flag-GSTP1(2M) (PRO123 and ALA163 were replaced by LYS and GLU, respectively), pcDNA3.1-Flag-GSTP1(3M) (PRO123, LEU160, and GLU163 were replaced by LYS, GLU, and ALA, respectively), pLKO.1-GSTP1-shRNA, pPLK/GFP + Puro-ATG7-shRNA, and pPLK/GFP + Puro-Beclin1shRNA were constructed according to standard techniques. In brief, Flag-tag and DNA fragment encoding mutant GSTP1 were generated by high fidelity PCR and cloned into pcDNA3.1 vector; DNA fragment encoding GSTP1shRNA, Beclin1-shRNA, ATG5-shRNA, ATG7-shRNA, TSC1-shRNA, and an unrelated shRNA sequence (Scramble-shRNA) were generated by high fidelity PCR and cloned into pLKO.1 and pPLK vectors separately. pcDNA3.1-Flag-AKT(T308D/S473D) plasmid was kindly provided by Dr. Qi Wang (Nanjing Normal University, China). All plasmids were verified by sequencing in Genscript Biotech and purified using the Endofree Plasmid Preparation kit (Qiagen, Germany).

\section{Co-immunoprecipitation and immunoblot analysis}

All cell pellets were rinsed with ice-cold PBS and lysed with the lysis buffer. Lysates were centrifuged $(12,500 \times g)$ at $4{ }^{\circ} \mathrm{C}$ for $15 \mathrm{~min}$. Proteins were immunoprecipitated with indicated antibodies. The precleared Protein A/G PLUSagarose beads (Santa Cruz Biotechnology, USA) were incubated with immunocomplexes and washed with the lysis buffer. The samples were separated by $12 \%$ SDSPAGE followed by transfer onto polyvinylidene fluoride (PVDF) membranes (ISEQ00010, Merck Millipore, USA), and detected by immunoblot analysis. The antibody-antigen complexes were visualized by the Luminescent Imaging Workstation (5200, Tanon, China) according to the manufacturer's instructions, using HRP-conjugated secondary antibodies. Quantification was directly performed on the blot using the ImageJ analysis software.

\section{Flow-cytometric apoptosis assays}

Experiments were performed by using an annexin V-FITC apoptosis detection kit (Vazyme Biotech, China) according to the manufacturer's protocol. Briefly, cells were harvested and washed, and then stained with annexin V and PI in binding buffer at room temperature for $15 \mathrm{~min}$. Samples were detected with the BD FACScalibur. For each sample, 8000 cells were analyzed. Data were analyzed by using FlowJo 7.6 Software, both early apoptotic cells and late apoptotic cells were nominated as apoptotic cells.

\section{Generation of stable cells}

MCF-7 and MCF-7/ADR cell lines stably expressing mCherry-EGFP-LC3B were established using lentiviral virus infection. Viruses (Cat No. LV00191-2e) were purchased from Biogot Technology, China. Lentiviral viruses were produced using a vector containing LC3B (pLVXmCherrym-C1-EGFP-LC3B) and two packaging vectors (pMD2, psPAX) in HEK 293T cells. After $48 \mathrm{~h}$ infection, both cell lines were maintained in puromycin $(2.5 \mu \mathrm{g} / \mathrm{mL})$ containing media for 4 weeks. After selection, cells were applied to the evaluation of mCherry-EGFP-LC3B expression and used for the following experiments.

\section{Immunofluorescence confocal microscopy}

MCF-7 and MCF-7/ADR cells were grown on glass coverslips in 24-well plates. After ADR treatment, cell were washed with phosphate buffer saline (PBS) three times, fixed with $4 \%$ formaldehyde for $15 \mathrm{~min}$, blocked with $5 \%$ BSA blocking buffer for $0.5 \mathrm{~h}$, and incubated with primary antibody overnight at $4{ }^{\circ} \mathrm{C}$ followed by fluorochrome-conjugated secondary antibody for $1 \mathrm{~h}$ followed by incubating with DAPI solution for $5 \mathrm{~min}$. 
a

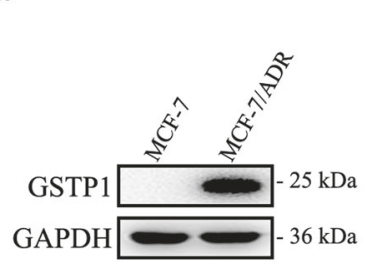

b

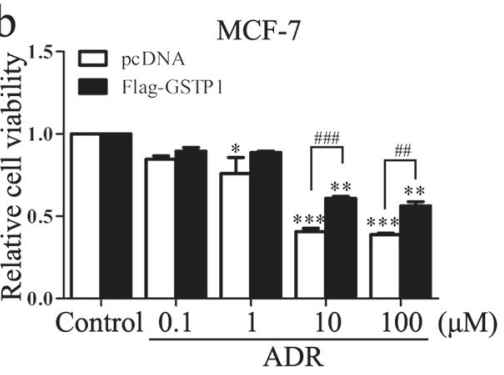

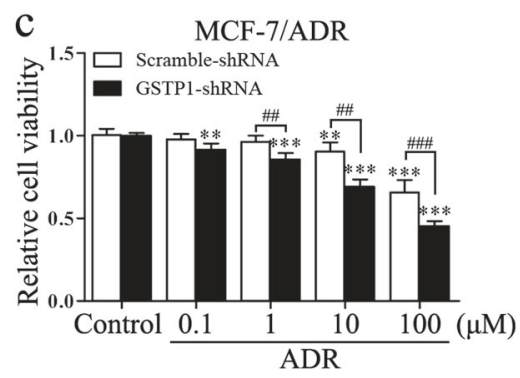

d

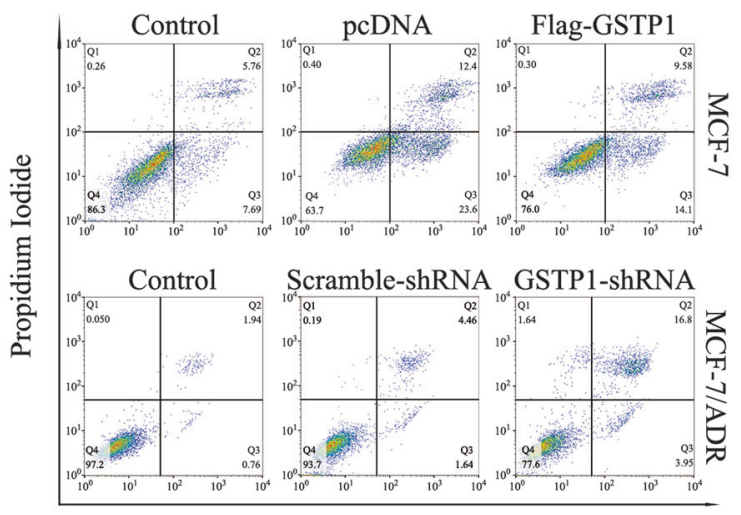

Annexin V-FITC

e

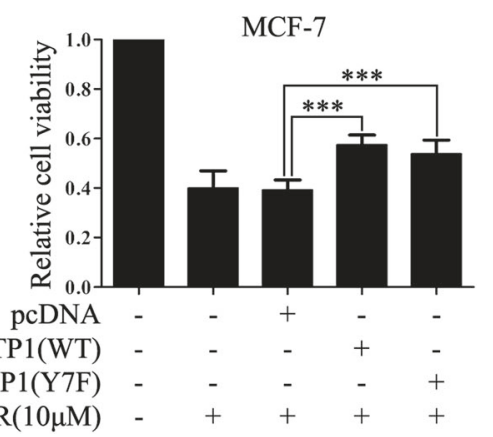

Fig. 1 GSTP1 contributes to the resistance of MCF-7 to ADR. a Immunoblot analysis of GSTP1 protein in MCF-7 and MCF-7/ADR cells. b, c MCF-7 cells transfected with pcDNA $(2 \mu \mathrm{g} / \mathrm{mL})$ or FlagGSTP1 $(2 \mu \mathrm{g} / \mathrm{mL})$ were treated with an indicated dose of ADR for $48 \mathrm{~h}$ (b). MCF-7/ADR cells transfected with Scramble-shRNA $(2 \mu \mathrm{g} / \mathrm{mL})$ or GSTP1-shRNA $(2 \mu \mathrm{g} / \mathrm{mL})$ plasmid were treated with $0,0.1,1,10$, $100 \mu \mathrm{M}$ ADR for $48 \mathrm{~h}$ (c). Cell viabilities were detected by MTT assay. d MCF-7 transfected with pcDNA $(2 \mu \mathrm{g} / \mathrm{mL})$ or FlagGSTP1 $(2 \mu \mathrm{g} / \mathrm{mL})$ plasmids and MCF-7/ADR cells transfected with Scramble-shRNA $(2 \mu \mathrm{g} / \mathrm{mL})$ or GSTP1-shRNA $(2 \mu \mathrm{g} / \mathrm{mL})$ plasmid were treated with $10 \mu \mathrm{M}$ ADR for $48 \mathrm{~h}$, and the apoptotic cells were

Finally, the coverslips were mounted onto slides using mounting medium, and the cells were examined using the Nikon A1 confocal laser microscope system (Tokyo, Japan).

\section{Transmission electron microscopy assay}

After being treated with $10 \mu \mathrm{M}$ ADR for $24 \mathrm{~h}$, MCF-7 and MCF-7/ADR cells were harvested. Cells were washed with cold PBS and fixed with fixation solution

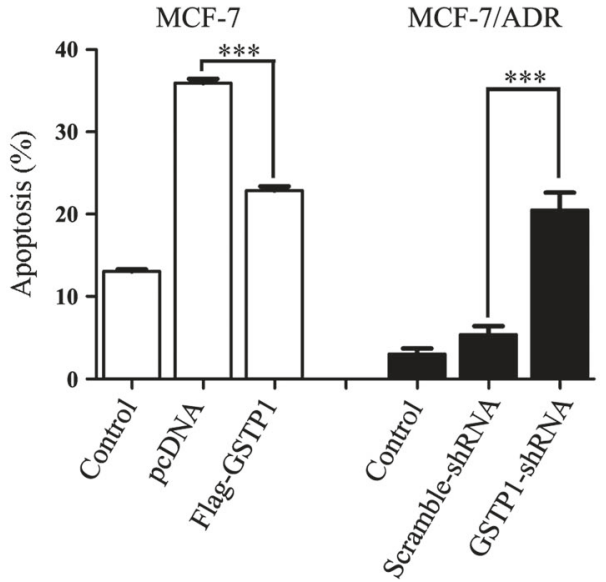

f

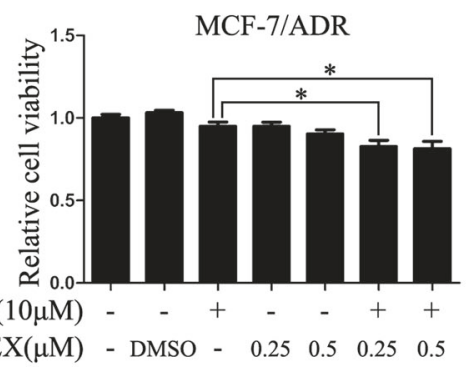

assessed by annexin V-FITC/PI staining. e MCF-7 cells were transfected with either pcDNA $(2 \mu \mathrm{g} / \mathrm{mL})$, wild type GSTP1 (WT) $(2 \mu \mathrm{g} /$ $\mathrm{mL}$ ), or catalytically inactive mutant GSTP1 (Y7F) $(2 \mu \mathrm{g} / \mathrm{mL})$, and $24 \mathrm{~h}$ after transfection cells were treated with $10 \mu \mathrm{M}$ ADR for $48 \mathrm{~h}$. Cell viability was detected using MTT assay. $\mathbf{f}$ MCF-7/ADR cells were pre-treated with NBDHEX for $2 \mathrm{~h}$ followed by treatment with ADR for $48 \mathrm{~h}$, and then the viability of cells was detected by MTT assay. Data of at least 3 independent experiments performed in duplicates is presented as mean \pm SEM. $* P<0.01, * * P<0.01, * * * P<0.001$ compared with control. ${ }^{\# !} P<0.01,{ }^{\# \# \#} P<0.001$ compared with control plasmid transfected cells

(4\% paraformaldehyde, $0.25 \%$ glutaraldehyde in $0.1 \mathrm{M}$ phosphate buffer) at $4{ }^{\circ} \mathrm{C}$ overnight. Then samples were embedded and sectioned, and then observed under a transmission electron microscope (Hitachi, Japan).

\section{Mass spectrometry analysis}

Proteins were immunoprecipitated using anti-GSTP1 or anti-Flag antibody. Protein A/G PLUS-agarose beads 
a

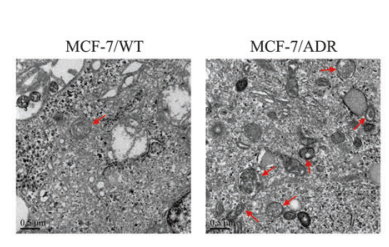

b

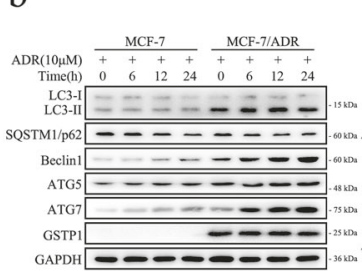

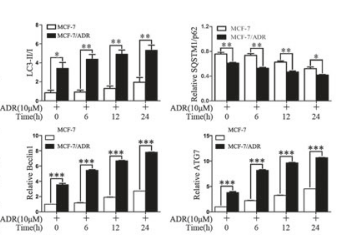

C

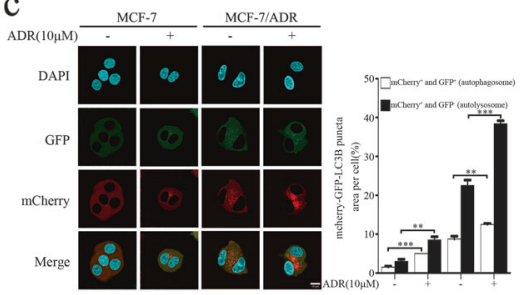

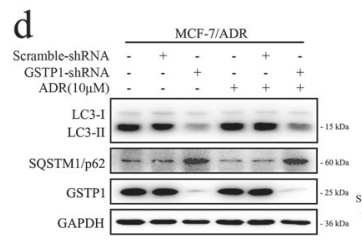

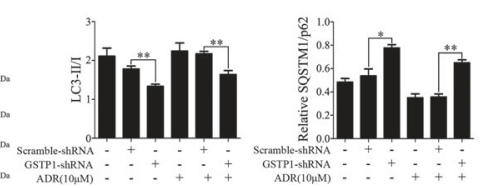

e
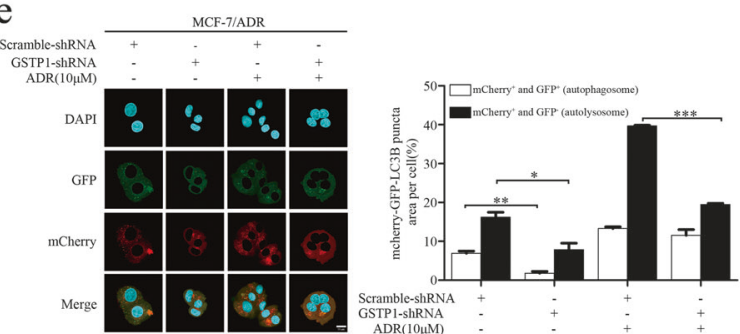

Fig. 2 GSTP1 promotes autophagy in breast cancer cells. a MCF-7 and MCF-7/ADR cells were treated with $10 \mu \mathrm{M}$ ADR for $24 \mathrm{~h}$ and then were subjected to transmission electron microscopy assay. The autophagosomes are indicated by red arrows. b MCF-7 and MCF-7/ ADR cells were treated with $10 \mu \mathrm{M}$ ADR for $0,6,12$, or $24 \mathrm{~h}$ followed by immunoblotting with indicated antibodies. c MCF-7 and MCF-7/ ADR cells that stably expressed mCherry-EGFP-LC3B were treated with $10 \mu \mathrm{M}$ ADR for $24 \mathrm{~h}$. After being stained with DAPI cells were detected under a confocal microscope. d MCF-7/ADR cells were transfected with Scramble-shRNA $(2 \mu \mathrm{g} / \mathrm{mL})$ or GSTP1-shRNA $(2 \mu \mathrm{g} / \mathrm{mL})$ plasmids and after $24 \mathrm{~h}$ cells were incubated with $10 \mu \mathrm{M}$ ADR followed by immunoblotting with indicated antibodies. e MCF7/ADR cells stably expressing mCherry-EGFP-LC3B were transfected

were incubated with proteins for $2 \mathrm{~h}$ and washed six times with the lysis buffer. $0.1 \mathrm{M}$ glycine- $\mathrm{HCl}$ was used to elute antigen from antibody and $1 \mathrm{M}$ Tris $-\mathrm{HCl}$ was added for neutralization. Following the proteins were immunoprecipitated with anti-p110 $\alpha$ antibody and were incubated with Protein A/G PLUS-agarose beads for $3 \mathrm{~h}$. The GSTP1 complexes were eluted from beads using $0.1 \mathrm{M}$ glycine- $\mathrm{HCl}$. Then, the endogenous and exogenous GSTP1 complexes were analyzed in linear mode by MALDI-8020 (Shimadzu Kratos, Manchester, UK).

\section{Protein-protein docking}

Crystal structure of GSTP1 was download from the Protein Data Bank (PDB ID:1eog). Use relevant visualization software to optimize the protein to obtain the desired GSTP1 enzyme monomer. The structure of the $\mathrm{C} 2$ domain f

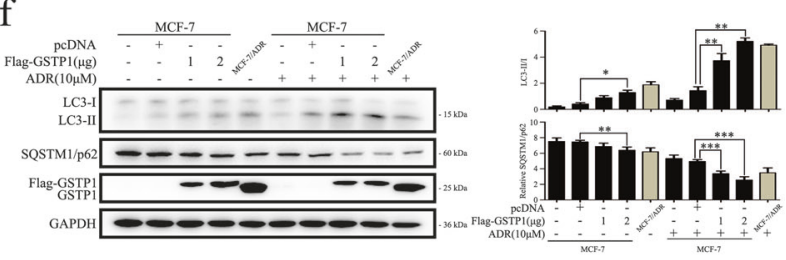

g

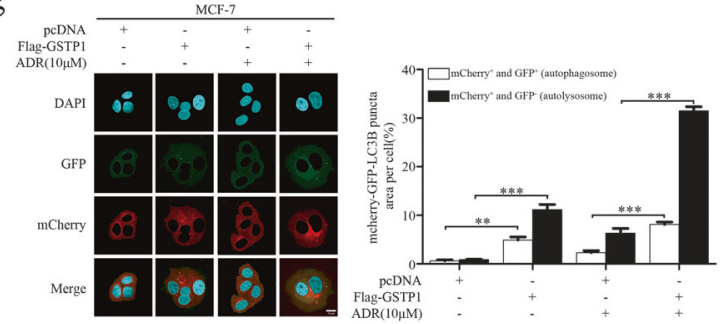

with Scramble-shRNA ( $2 \mu \mathrm{g} / \mathrm{mL})$ or GSTP1-shRNA $(2 \mu \mathrm{g} / \mathrm{mL})$ plasmid and after $24 \mathrm{~h}$ were stimulated with $10 \mu \mathrm{M}$ ADR for $24 \mathrm{~h}$. After being stained with DAPI cells were detected under a confocal microscope. f MCF-7 cells were transfected with pcDNA $(2 \mu \mathrm{g} / \mathrm{mL})$ or Flag-GSTP1 $(2 \mu \mathrm{g} / \mathrm{mL})$, and after $24 \mathrm{~h}$ cells were incubated with 10 $\mu \mathrm{M}$ ADR for $24 \mathrm{~h}$. The cell lysis was applied to immunoblotting with indicated antibodies. $\mathrm{g}$ MCF-7 cells stably expressing mCherry-EGFPLC3B were transfected with pcDNA $(2 \mu \mathrm{g} / \mathrm{mL})$ or Flag-GSTP1 $(2 \mu \mathrm{g} / \mathrm{mL})$, and after $24 \mathrm{~h}$ were incubated with $10 \mu \mathrm{M}$ ADR for $24 \mathrm{~h}$. After being stained with DAPI cells were observed under a confocal microscope. Data of 3 independent experiments is presented as mean \pm SEM. $* P<0.05, * * P<0.01, * * * P<0.01$ compared with control

from human PI3-kinase p110 subunit alpha was obtained from PDB with ID 2enq. Protein-protein docking of p110- $\alpha$-C2 domain to GSTP1 was performed with Discovery Studio (v.2.5.5), then set parameters, and 2000 poses were generated. The initial screening of docking results is based on shape matching function ZDock (binding site RMSD) scores and filter out the best 50 docked complexes, and then re-scored by calculating electrostatic energy, VDW, and desolvation energy to screen out the most forward three binding sites of GSTP1.

\section{Statistical analysis}

All statistical tests were performed with GraphPad Prism 5.0. Data were expressed as mean \pm SEM. Statistical significance was determined using unpaired Student's twotailed $t$-test for two data sets. Statistical significance was defined as $* P<0.05, * * P<0.01, * * * P<0.01$. 


\section{Results}

\section{GSTP1 protects MCF-7 cells from ADR-induced cell death}

Consistent with the previous report [12], our immunoblotting experiments demonstrated that ADR-resistant MCF-7/ ADR cells had much higher GSTP1 level than ADRsensitive MCF-7 cells (Fig. 1a). Furthermore, all MTT detection, flow-cytometric apoptosis assay, and morphological observation showed that MCF-7 cells were more sensitive to ADR than MCF-7/ADR cells (Supplementary Figure S1A-D). To explore whether the cellular level of GSTP1 is related with the resistance of MCF-7 to ADR, we transfected MCF-7 cells with Flag-GSTP1 plasmid and then treated cells with ADR. Both MTT and flow-cytometric apoptosis assay showed that forced expression of FlagGSTP1 significantly inhibited ADR-induced cell death (Fig. 1b, d). When we knock down GSTP1 level in MCF-7/ ADR cells by transfecting GSTP1-shRNA plasmid, the resistance of MCF-7/ADR cells to ADR significantly reduced (Fig. 1c, d). These data indicated that high level of GSTP1 might protect MCF-7 cells against cytotoxicity of ADR. ADR was not the substrate of GSTP1 transferase activity suggesting the ADR resistance of MCF-7 was independent of GSTP1 catalytic activity [13]. GSTP1(Y7F) is a catalytically inactive mutant, in which phenylalanine replaced tyrosine in the seventh amino-terminal position. As shown in Fig. 1e, overexpressed GSTP1(Y7F) in MCF-7 cells acted as similar as wild type GSTP1(GSTP1(WT)) in reducing sensibility of cells to ADR. Furthermore, we pretreated MCF-7/ADR cells with NBDHEX, a GSTP1 inhibitor, cell resistance to ADR only slightly reduced (Fig. 1f). MDA-MB-468 is another kind of human breast cancer cell line which has detectable but very low GSTP1 level (Supplementary Figure S1E). We found that both GSTP1(WT) and GSTP1(Y7F) overexpression reduced ADR-induced cell death (Supplementary Figure S1F). These results indicated that GSTP1 contributes to protect breast cancer cells against ADR treatment in a transferase independent way.

\section{GSTP1 promotes autophagy in MCF-7 and MCF-7/ADR cells}

To understand the mechanism involved in GSTP1-induced resistance of human breast cancer cells to ADR, we first observed the morphology of ADR-sensitive MCF-7 and ADR-resistant MCF-7/ADR cells. The electron microscopy observation demonstrated that MCF-7/ADR cells had a higher autophagy level compared with MCF-7 cells under ADR stimulation (Fig. 2a). Since autophagy has been found to relate with drug resistance of cancer cells $[19,20]$, we explored whether GSTP1 enhanced autophagy. The amount of LC3-II, a key protein related with autophagy, represents both the number of autophagosomes and SQSTM1/p62 (sequestosome 1) protein selectively degraded by autophagy [29]. Results from the immunoblotting assay showed that MCF-7/ADR cells had higher ratio of LC3-II/I and lower SQSTM1/p62 protein level compared with MCF-7 cells before and after ADR treatment (Fig. 2b). Consistent with this result, higher Beclin-1, ATG5, and ATG7 levels were observed in MCF-7/ADR cells than MCF-7 cells (Fig. 2b). Furthermore, the confocal microscopy observation demonstrated that the numbers of LC3 puncta in MCF-7/ADR cells were also much more than MCF-7 (Supplementary Figure S2A).

To compare actual autophagic flux in MCF-7 and MCF7/ADR cells, we established mCherry-EGFP-LC3B stably expressing MCF-7 and MCF-7/ADR cell lines. Since the GFP fluorescence quenches rapidly in acidic conditions of the lysosome lumen and mCherry is stable, thus the yellow punctum, which is colocalized of both GFP and mCherry fluorescence, indicates a compartment, such as the phagophore or an autophagosome, that has not fused with a lysosome, whereas the red punctum from an mCherry signal indicates the fusion of autophagosomes and lysosomes [30]. Compared with MCF-7 cells, MCF-7/ADR cells showed a higher level of accumulation of mature autolysosomes defined by red puncta and autophagosomes identified by yellow puncta before ADR treatment, and after ADR stimulation, there were fewer yellow puncta compared with red puncta in MCF-7/ADR cells. These results indicated that MCF-7/ADR cells had higher autophagic level than MCF-7 cells and ADR treatment enhanced autophagy flux (Fig. 2c).

We then knocked down GSTP1 level in MCF-7/ADR cells by transfecting plasmid-expressing GSTP1 shRNA. As shown in Fig. 2d, the ratio of LC3-II/I significantly reduced and SQSTM1/p62 level significantly increased along with GSTP1 RNAi. Furthermore, confocal microscopy showed a decrease of LC3 puncta induced by GSTP1 RNAi (Supplementary Figure S2B). ADR-stimulated autophagic flux also diminished by GSTP1 RNAi in MCF-7/ADR cells (Fig. 2e). As expected, the overexpression of GSTP1 in MCF-7 cells increased the ratio of LC3-II/I and reduced the SQSTM1/p62 level (Fig. 2f). Results from confocal microscopy showed that overexpressed GSTP1 in MCF-7 cells increased LC3 puncta (Supplementary Figure S2C) and enhanced autophagic flux (Fig. 2g). Above experiments on both MCF-7 and MCF-7/ADR cells demonstrated that GSTP1 promoted autophagy. In the subsequent experiments, we found that GSTP1-induced autophagy was independent of its catalytic activity (Supplementary Figure S3A, B). GSTP1 elevated autophagy was confirmed in MDA-MB-468 cells (Supplementary Figure S3C). 
a

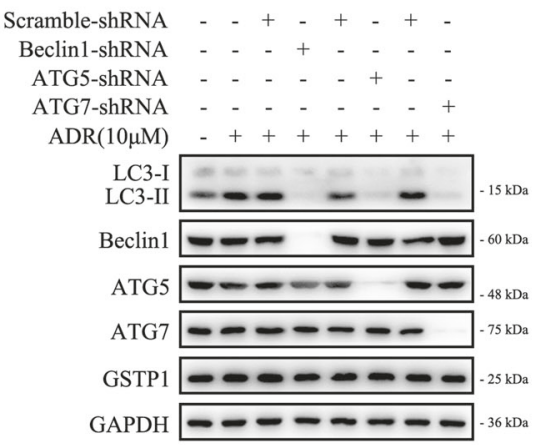

c

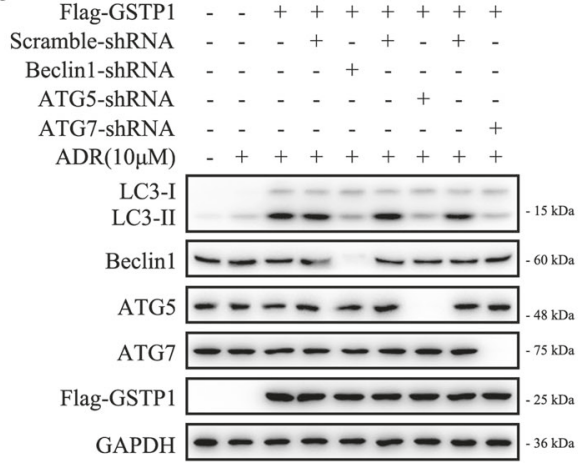

Fig. 3 The resistance of breast cancer cells to ADR was diminished by inhibition of GSTP1 enhanced autophagy. a MCF-7/ADR cells were transfected with Beclin1-shRNA ( $2 \mu \mathrm{g} / \mathrm{mL})$, ATG5-shRNA $(2 \mu \mathrm{g} / \mathrm{mL})$, ATG7-shRNA $(2 \mu \mathrm{g} / \mathrm{mL})$, and equal Scramble-shRNA plasmids, respectively and then were treated with $10 \mu \mathrm{M}$ ADR for $24 \mathrm{~h}$ followed by immunoblotting with LC3 antibody. b MCF-7/ADR cells were transfected with Beclin1-shRNA $(2 \mu \mathrm{g} / \mathrm{mL})$, ATG5-shRNA $(2 \mu \mathrm{g} / \mathrm{mL})$, ATG7-shRNA $(2 \mu \mathrm{g} / \mathrm{mL})$, and equal Scramble-shRNA, plasmids respectively and then were treated with $10 \mu \mathrm{M}$ ADR for $24 \mathrm{~h}$. The apoptotic cells were assessed by annexin V-FITC/PI staining. c MCF-7 cells were transfected with Scramble-shRNA $(2 \mu \mathrm{g} / \mathrm{mL})$, Beclin1-

\section{Autophagy enhanced by GSTP1 contributes to ADR resistance of MCF-7}

Above results indicated that GSTP1 promoted autophagy in MCF-7 cells. To evaluate whether GSTP1-induced high level of autophagy contributed to ADR resistance of MCF7, we knocked down autophagy-related protein, Beclin1, ATG5, or ATG7, respectively, both in MCF-7/ADR cells and MCF-7 cells transfected with Flag-GSTP1. As shown in Fig. 3, autophagy inhibition by knockdown of Beclin1, ATG5, or ATG7 increased ADR-induced cell death both in MCF-7/ADR and GSTP1 overexpressed MCF-7 cells (Fig. 3). For further investigation, we treated cells with autophagy inhibitor 3-methyladenine (3-MA) [31] or chloroquine (CQ) [32]. Results showed that both 3-MA and CQ significantly inhibited GSTP1-induced increase of autophagy both in MCF-7 cells transfected with FlagGSTP1 (Supplementary Figure S4A and Figure S5A) and MCF-7/ADR cells (Supplementary Figure S4D and
Figure S5D). and importantly both 3-MA and CQ apparently decreased ADR resistance of both MCF-7 cells transfected with Flag-GSTP1 (Supplementary Figure S4B and $\mathrm{C}$, Figure S5B and C) and MCF-7/ADR cells (Supplementary Figure S4E and F, Figure S5E and F). Furthermore, autophagy blockage in GSTP1 overexpressed MDA-MB-468 cells also resulted in the reverse of the resistance to ADR (Supplementary Figure S6A, B). All these results indicated that GSTP1 protected breast cancer cells against ADR-induced cell death through enhancing autophagy.

\section{GSTP1 enhances autophagy through regulating PI3K-Akt-mTOR signal cascade}

The mammalian target of rapamycin (mTOR) plays a crucial role in regulating autophagy [33]. Rapamycin inhibits mTOR function followed by autophagy induction [22]. We compared the mTOR activation in both MCF-7 cells and 

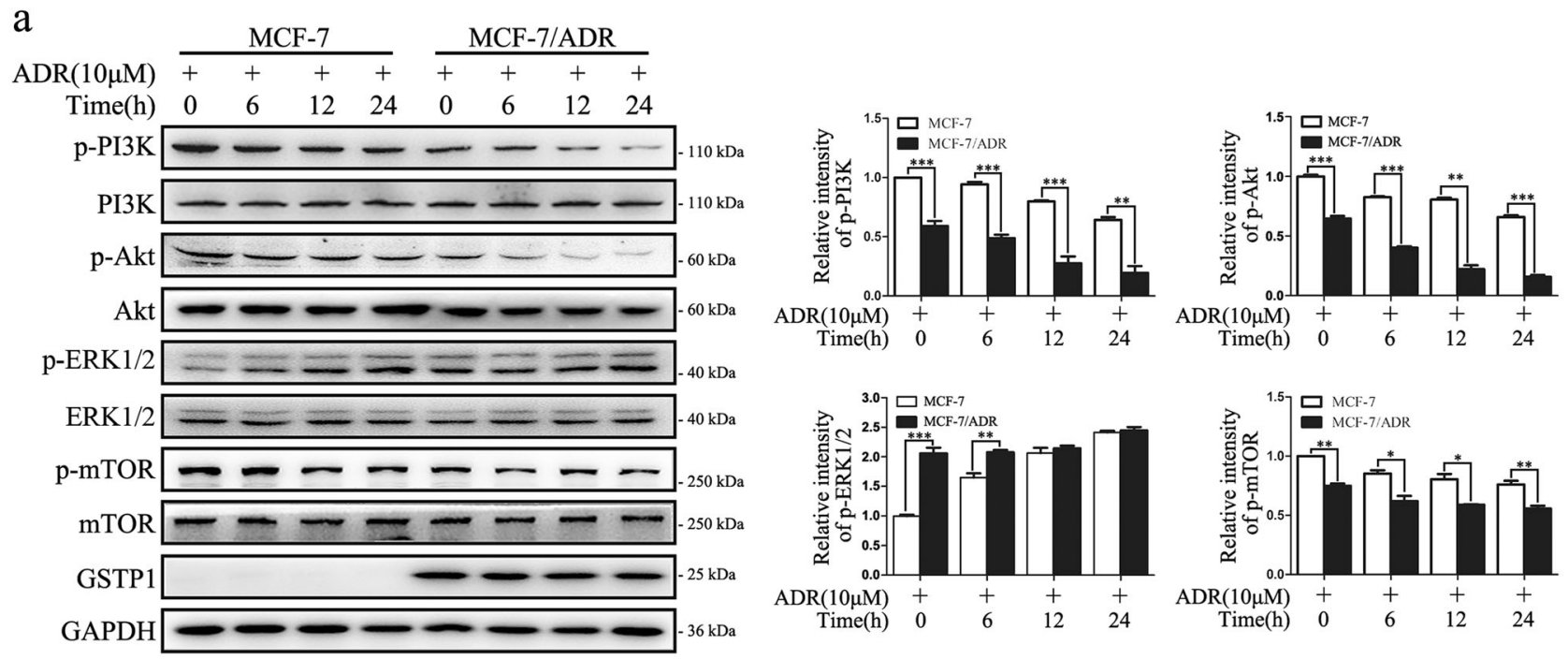

$\mathrm{b}$
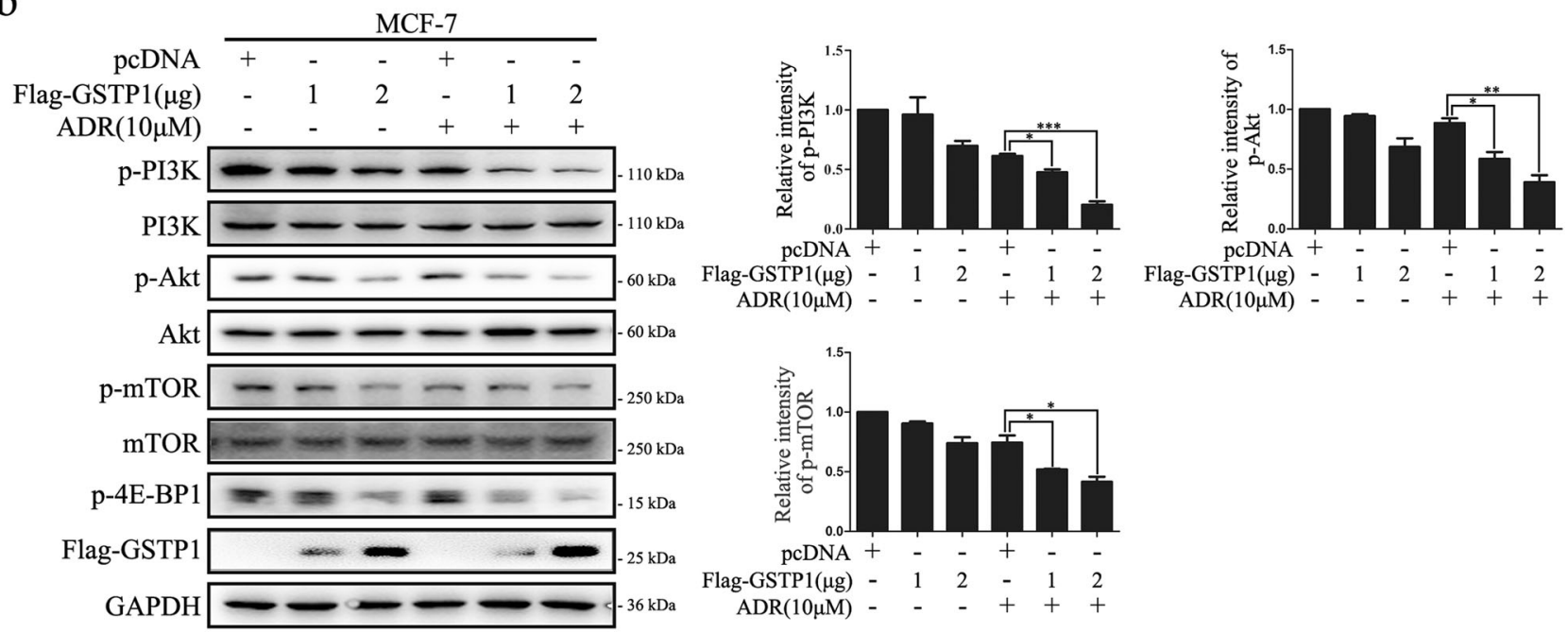

C

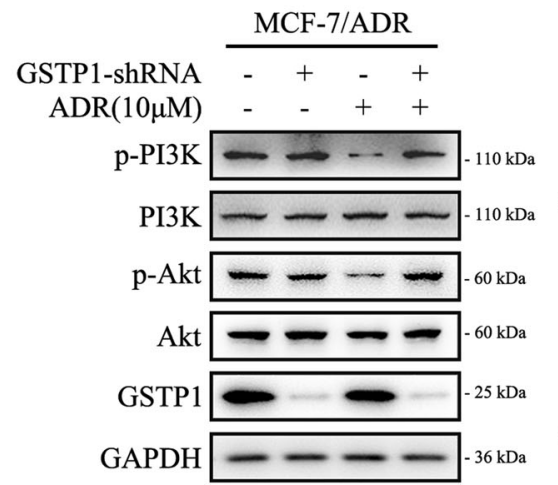

Fig. 4 GSTP1 regulates PI3K-Akt-mTOR signal cascade. a MCF-7 and MCF-7/ADR cells were treated with $10 \mu \mathrm{M}$ ADR for indicated time and then were subjected to immunoblotting with p-PI3K/PI3K, pAKT/AKT, p-ERK/ERK, p-mTOR/mTOR, and GSTP1 antibodies. b MCF-7 cells were transfected with pcDNA $(2 \mu \mathrm{g} / \mathrm{mL})$ or FlagGSTP1 $(2 \mu \mathrm{g} / \mathrm{mL})$ plasmids followed by treatment with $10 \mu \mathrm{M}$ ADR for $24 \mathrm{~h}$. The cell lysates were subjected to immunoblotting with indicated antibodies. c MCF-7/ADR cells transfected with ScrambleshRNA d

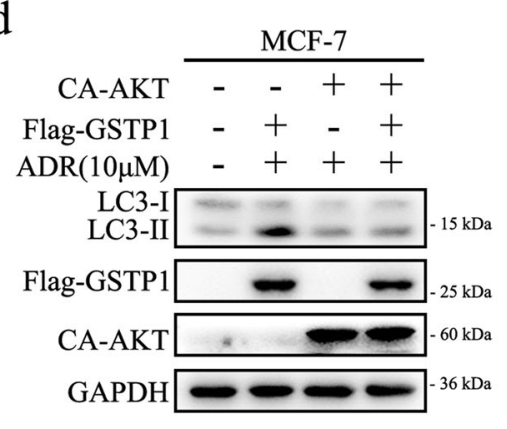

$(2 \mu \mathrm{g} / \mathrm{mL})$ or GSTP1-shRNA $(2 \mu \mathrm{g} / \mathrm{mL})$ plasmids were treated with $10 \mu \mathrm{M}$ ADR for $24 \mathrm{~h}$ followed by immunoblotting with indicated antibodies. d MCF-7 cells were co-transfected with Akt mutant plasmid, CA-AKT (T308D/S473D) $(1.5 \mu \mathrm{g} / \mathrm{mL})$, and Flag-GSTP1 $(2 \mu \mathrm{g} / \mathrm{mL})$ plasmid, and then were treated with $10 \mu \mathrm{M}$ ADR for $24 \mathrm{~h}$ followed by immunoblotting with indicated antibodies. Data of 3 independent experiments is presented as mean \pm SD. $* P<0.05$, $* * P<$ $0.01, * * * P<0.001$ compared with control 


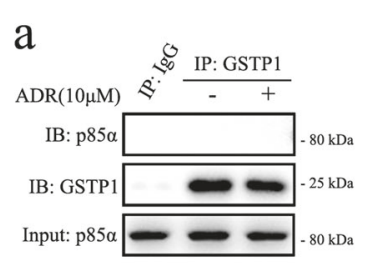

e

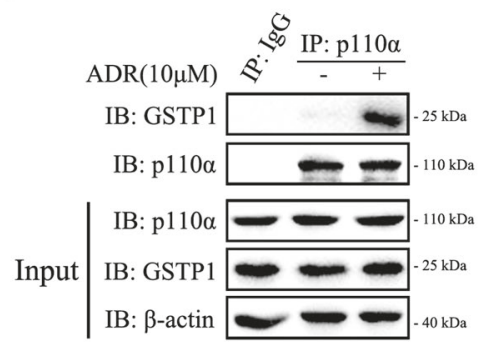

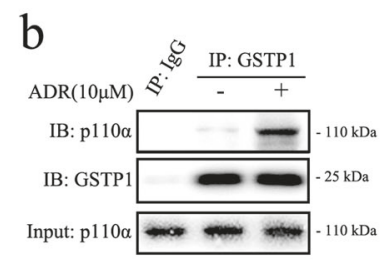

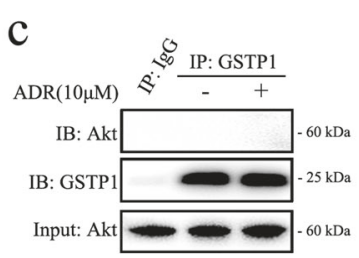

d

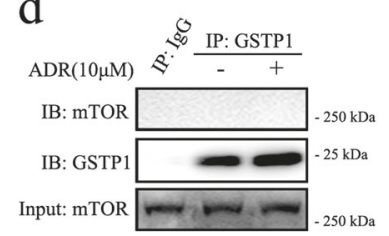

f

p110 $\alpha$
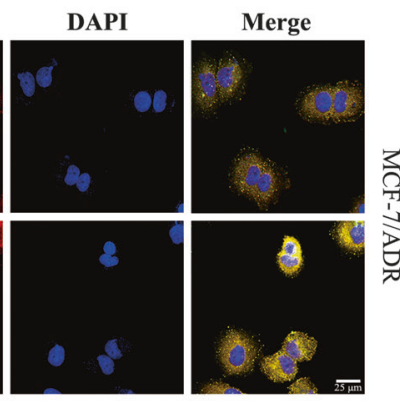

g

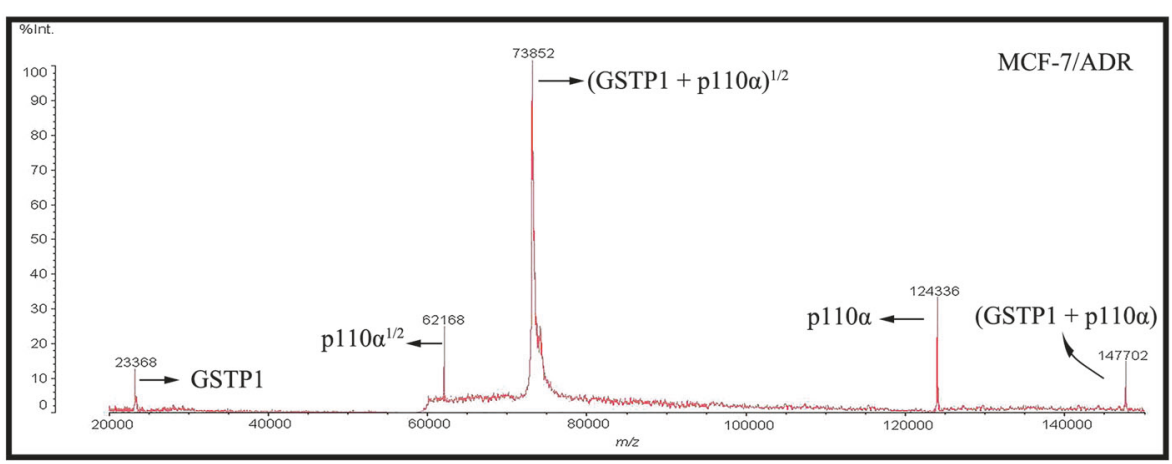

$\mathrm{h}$

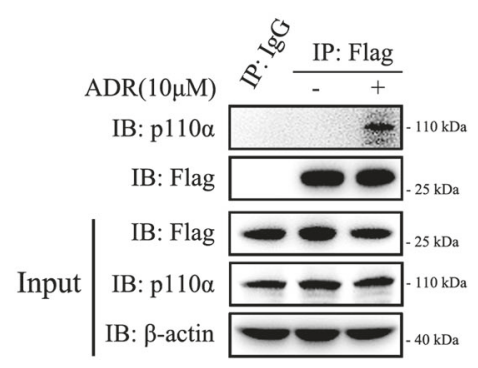

$\mathrm{i}$

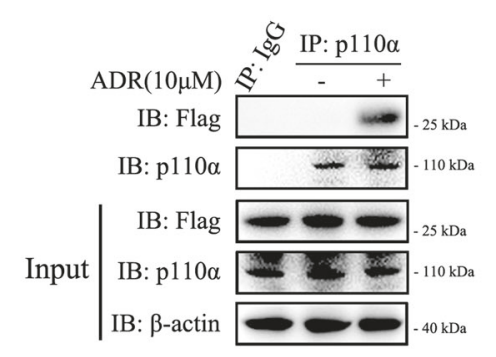

j

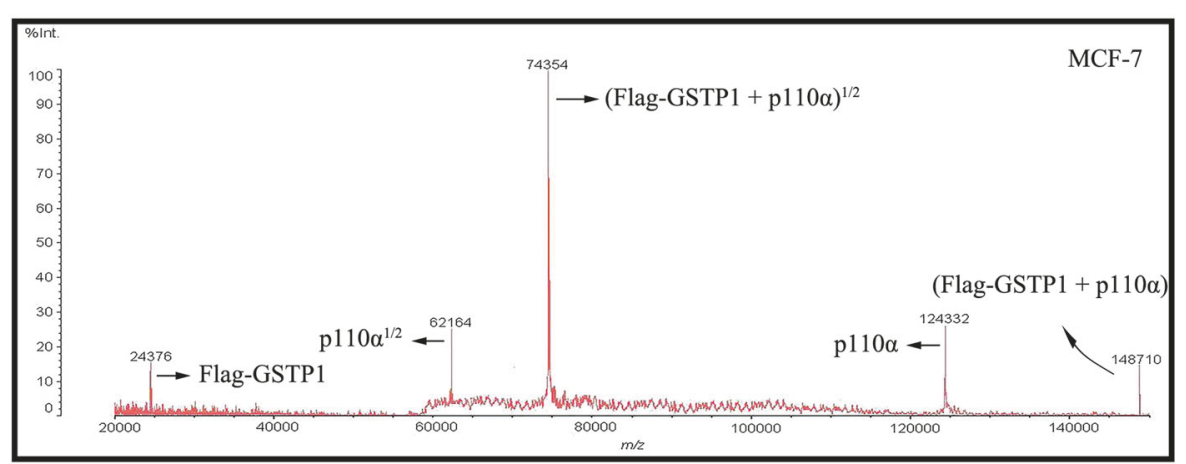

MCF-7/ADR cells under ADR stimulation using immunoblotting detection. Results showed that the ratio of phosphorylated mTOR to mTOR was apparently lower in
MCF-7/ADR cells than in the MCF-7 cells before and after ADR treatment (Fig. 4a), suggesting that GSTP1-induced high autophagy level in MCF-7/ADR cells was related to 
Fig. 5 GSTP1 associates with p110 $\alpha$ of PI3K to prevent PI3K-AktmTOR signaling. a-d Lysates from MCF-7/ADR cells stimulated with ADR or not were subjected to immunoprecipitation with anti-GSTP1 and were detected by immunoblotting with anti-p85 $\alpha$ (a), anti-p110 $\alpha$ (b), anti-Akt (c), anti-mTOR (d), and anti-GSTP1 antibodies. e Lysates from MCF-7/ADR cells stimulated with ADR or not were subjected to immunoprecipitation with anti-p110 $\alpha$ and were detected by immunoblotting with anti-p110 $\alpha$ and anti-GSTP1 antibodies. f MCF-7/ADR cells were stimulated with $10 \mu \mathrm{M}$ ADR for $24 \mathrm{~h}$ followed by immunostaining with GSTP1 and p110 $\alpha$ antibodies, and then with FITC-conjugated Donkey Anti-Goat and Alexa Fluor 594conjugated Goat anti-Rabbit secondary antibodies. After being stained with DAPI cells were observed under a confocal microscope. $g$ The endogenous GSTP1 complex was analyzed by MALDI-TOF. h, i MCF-7 cells were transfected with GSTP1 $(2 \mu \mathrm{g} / \mathrm{mL})$ or pcDNA $(2 \mu \mathrm{g} /$ $\mathrm{mL}$ ) and then were stimulated with $10 \mu \mathrm{M}$ ADR or not. Immunoprecipitation was performed with anti-p110 $\alpha$ and anti-Flag antibodies followed by immunoblotting with the anti-GSTP1, anti-p110 $\alpha$, and anti-Flag antibodies. $\mathbf{j}$ The exogenous GSTP1 complex was analyzed by MALDI-TOF

the low level of mTOR activation. As mTOR was activated by PI3K-Akt or ERK pathway [34, 35], we next analyzed which pathway was involved in mTOR activation, and found that the phosphorylation levels of PI3K and Akt were lower in MCF-7/ADR than in MCF-7 (Fig. 4a). However, phosphorylated ERK1/2 level in MCF-7 cells was as same as in MCF-7/ADR cells $12 \mathrm{~h}$ after ADR stimulation and ADR did not affect ERK1/2 phosphorylation in MCF-7 cells suggesting mTOR activation was not dependent on ERK1/2 pathway. Further experiments showed that transfection of GSTP1 in MCF-7 cells significantly inhibited the activation of PI3K-Akt-mTOR pathway (Fig. 4b), in contrary, GSTP1 RNAi in MCF-7/ADR cells reversed ADRinduced inhibition of PI3K-Akt-mTOR signaling (Fig. 4c). To further evaluate the effect of GSTP1 on PI3K-AktmTOR pathway, we co-transfected a constitutively active form of Akt (CA-AKT) and Flag-GSTP1 plasmids into MCF-7 cells and then conducted immunoblotting detection. The results showed that CA-AKT prevented GSTP1induced autophagy elevation (Fig. 4d). Since Akt can regulate autophagy independently of mTOR pathway, we then genetically inhibited mTOR upstream regulated protein tuberous sclerosis-1 (TSC1). The results showed that TSC1 knockdown significantly inhibited GSTP1 enhanced autophagy and drug resistance (Supplementary Figure S7). All these results indicated that GSTP1 promoted autophagy through inhibiting the activation of PI3K-Akt-mTOR but not ERK1/2-mTOR pathway.

\section{GSTP1 binds p110a subunit of PI3K via its C-terminal domain to prevent PI3K-Akt-mTOR signaling}

To elucidate the mechanism by which GSTP1 regulated PI3KAkt-mTOR signaling, we performed immunoprecipitation experiments to detect the specific association of endogenous GSTP1 with PI3K, Akt, and mTOR in MCF-7/ADR cells. Results indicated that there was no association between GSTP1 and $\mathrm{p} 85 \alpha$ subunit of PI3K, Akt, and mTOR under ADR stimulation or not (Fig. 5a, c, d). Interestingly, a weak association of GSTP1 with p110 $\alpha$ subunit of PI3K was detected in MCF7/ADR cells without ADR treatment, but the association of GSTP1 and $p 110 \alpha$ remarkably increased after ADR stimulation (Fig. 5b, e). Furthermore, the immunofluorescence assay demonstrated the co-localization (yellow) of GSTP1 (green) and $\mathrm{p} 110 \alpha$ (red) (Fig. 5f). These results suggested the binding of GSTP1 with p110 $\alpha$ subunit of PI3K. To confirm the interaction between GSTP1 with p110 $\alpha$, we conducted the mass spectrum of MALDI-TOF detection. As expected, endogenous GSTP1 in MCF-7/ADR cells associated with p110 $\alpha$ (Supplementary Figure S8A and B, Fig. 5g). Furthermore, when MCF-7 cells were transfected with Flag-GSTP1, both immunoprecipitation and mass spectrum of MALDI-TOF experiments demonstrated that the overexpressed exogenous GSTP1 in MCF-7 cells also bound to p110 $\alpha$ (Fig. 5h-j, Supplementary Figure S8C). Altogether, above results suggested that GSTP1 specifically interacted with p $110 \alpha$ subunit of PI3K, the upstream of mTOR.

To analyze which region of GSTP1 was necessary for binding $\mathrm{p} 110 \alpha$, protein molecular docking simulation was conducted and visualized by Discovery Studio software (Fig. 6a). The most possible binding sites of GSTP1 was PRO123, LEU160, and GLU163, according to high ZDock scores, high density values, and low ZRank scores (Supplementary Table S1). To verify whether these residues are necessary for the interaction of GSTP1 with p110 $\alpha$, we constructed two GSTP1 mutant plasmids, GSTP1(P123D) (PRO123 was replaced by ASP) and GSTP1(P123K) (PRO123 was replaced by LYS), and transfected them into MCF-7 cells respectively. Following immunoprecipitation and immunoblotting experiments showed that GSTP1 (P123D) acted as same as GSTP1(WT) in associating with $\mathrm{p} 110 \alpha$ while the interaction of GSTP1(P123K) with $\mathrm{p} 110 \alpha$ slightly reduced (Supplementary Figure S9A and B). We then constructed GSTP1(2M) (PRO123 and ALA163 were replaced by LYS and GLU respectively) and GSTP1(3M) (PRO123, LEU160, and GLU163 were replaced by LYS, GLU, and ALA, respectively) mutants (Supplementary Figure S10), and transfected them into MCF-7 cells respectively. Interestingly, the immunoprecipitation results showed that the complex of GSTP1(2M)/p110 $\alpha$ was fewer than the complex of GSTP1(WT)/p110 $\alpha$ and the complex of GSTP1(3M)/p110 $\alpha$ was almost not detected (Fig. 6b-e), suggesting that these amino acids were essential for the association of GSTP1 and p110 $\alpha$.

We then evaluated the importance of these amino acids for GSTP1 to enhance autophagy and protect MCF-7 cells against ADR-induced cell death. Compared with GSTP1 
a
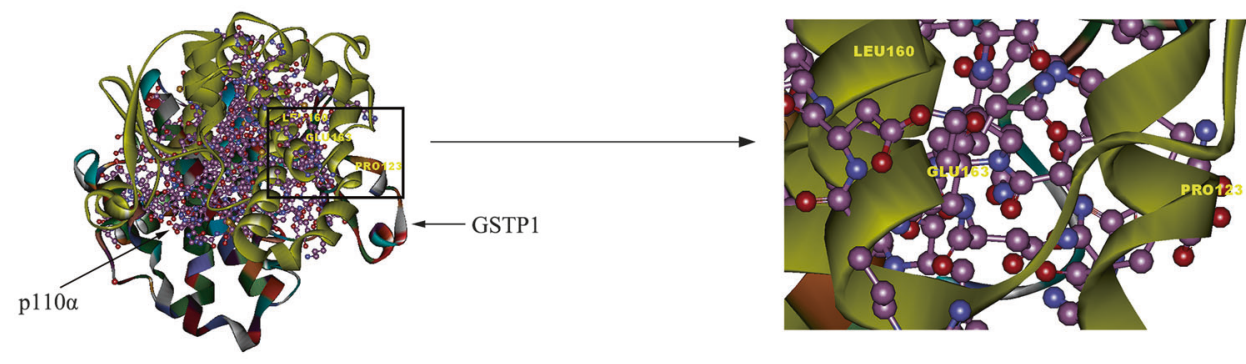

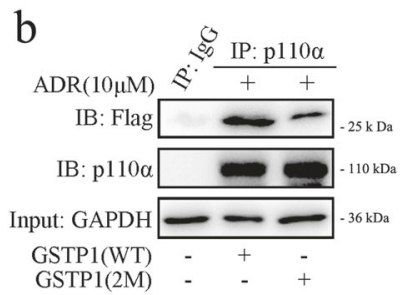

f

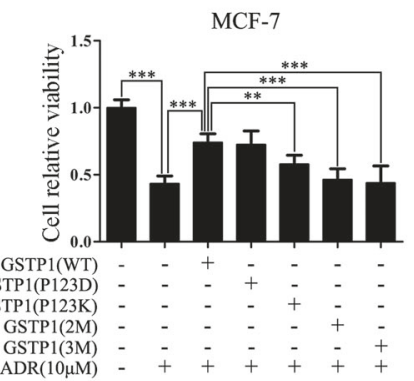

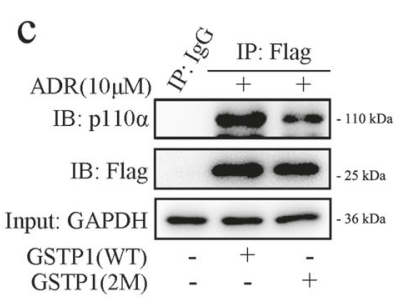

$\mathrm{g}$

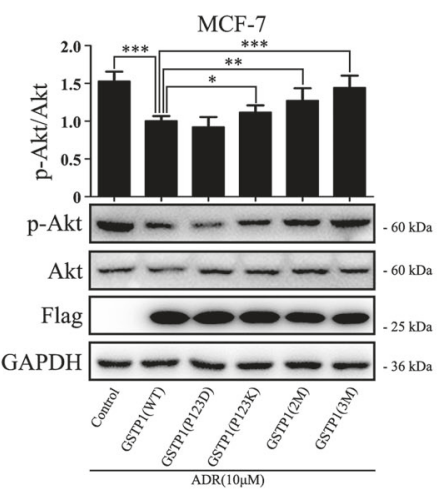

d

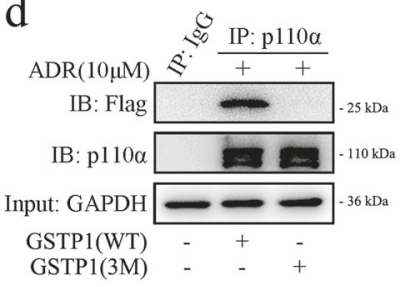

$\mathrm{h}$

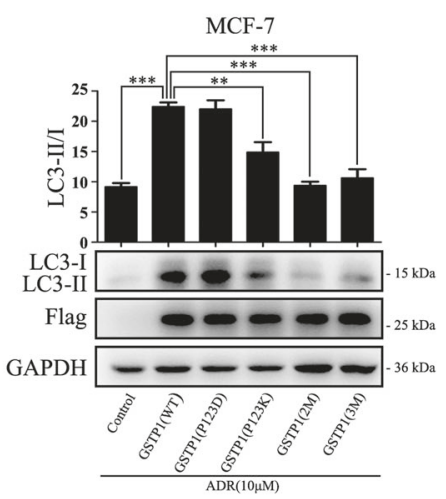

Fig. 6 Proline123, Leucine160, and Glutamic163 of GSTP1 are pivotal for the interaction between GSTP1 and p110 $\alpha$. a Schematic presentation of model for initial binding of GSTP1 (ribbon) and p1 $10 \alpha$ (ball-and-stick) and top 3 scored interacting residues of GSTP1. b, c MCF-7 cells were transfected with GSTP1 (WT) $(2 \mu \mathrm{g} / \mathrm{mL})$ or GSTP1 (2M) $(2 \mu \mathrm{g} / \mathrm{mL})$ and stimulated with $10 \mu \mathrm{M}$ ADR. Lysates were subjected to immunoprecipitation with anti-p110 $\alpha$ antibody (b), anti-Flag (c), and rabbit immunoglobulin $\mathrm{G}$ (rIgG). The precipitates were analyzed by immunoblotting with p110 $\alpha$, GSTP1, and GAPDH (used as the internal control) antibodies. d, e MCF-7 cells were transfected with GSTP1 (WT) $(2 \mu \mathrm{g} / \mathrm{mL})$ or GSTP1 (3M) $(2 \mu \mathrm{g} / \mathrm{mL})$ and stimulated with $10 \mu \mathrm{M}$ ADR. Lysates were subjected to immunoprecipitation with p110 $\alpha$ (d), Flag (e), and rabbit immunoglobulin G (rIgG). The precipitates were analyzed by immunoblotting with p110 $\alpha$, GSTP1, and GAPDH antibodies. f MCF-7 cells were transfected with GSTP1 (WT) $(2 \mu \mathrm{g} / \mathrm{mL})$, GSTP1 (P123D) $(2 \mu \mathrm{g} / \mathrm{mL})$, GSTP1 (P123K) $(2 \mu \mathrm{g} / \mathrm{mL})$, GSTP1 (2M) $(2 \mu \mathrm{g} / \mathrm{mL})$, or GSTP1 (3M) $(2 \mu \mathrm{g} / \mathrm{mL})$ plasmids and then treated with $10 \mu \mathrm{M}$ ADR for $48 \mathrm{~h}$. Cell viability was detected using MTT assay. g, h MCF-7 cells were transfected with either GSTP1 (WT) $(2 \mu \mathrm{g} / \mathrm{mL})$, GSTP1 (P123D) $(2 \mu \mathrm{g} / \mathrm{mL})$, GSTP1 (P123K) $(2 \mu \mathrm{g} / \mathrm{mL})$, GSTP1 (2M) $(2 \mu \mathrm{g} / \mathrm{mL})$, or GSTP1 (3M) $(2 \mu \mathrm{g} / \mathrm{mL})$ plasmids were subjected to immunoblotting with p-Akt $(\mathbf{g})$, LC3B (h), or GAPDH antibodies. Data of 3 independent experiments is presented as mean \pm SEM. $* P<0.05 ; * * P<0.01 ; * * * P<0.001$ compared with control

located in C terminal of GSTP1, are important for GSTP1 to interact with $\mathrm{p} 110 \alpha$, and promote autophagy and drug resistance in MCF-7.

\section{Discussion}

To date, chemoresistance is still one of the main problems in cancer therapy. Since high expression of GSTP1 was detected in many tumors and cancer cell lines including ovarian, non-small-cell lung (NSCLC), breast, colon, 
pancreas, and lymphomas and in a wide range of drugresistant cell lines and tumors, GSTP1 is of particular interest with regard to cancer [8]. GSTP1 was originally identified as a cytosolic phase II detoxification enzyme, thus chemoresistance has been considered to relate with its enzyme activity [36]. However, most cancer drugs are not good substrates for GSTP1, the reason(s) for the high levels of expression of GSTP1 are not always clear. On the other hand, GSTP1 has established important roles in the regulation of kinase activity such as MAPKs and posttranslational S-glutathionylation reactions [14, 17]. Some researchers conjectured that capacity of GSTP1 to regulate kinase pathways and S-glutathionylation of proteins may contribute to the GSTP1 overexpressing, drug-resistant phenotype [17, 37, 38].

ADR-resistant MCF-7/ADR cells have high level of GSTP1 compared with ADR-sensitive MCF-7 cells, which provided a suitable model for analyzing the mechanism. In the present study, the results from both RNAi in MCF-7/ ADR cells and overexpression in MCF-7 cells demonstrated that GSTP1 played a key role in the resistant of MCF-7 cells to ADR. The results also showed that the effect of GSTP1 on the drug resistance in MCF-7/ADR cells was independent of its enzyme activity, which was coincident with the previous report that ADR was not the substrate of GSTP1 [14]. Interestingly, we found for the first time that the high level of GSTP1 contributed to the high level of autophagy in MCF-7 cells. The chemodrug treatment may induce stress tolerance that enables tumor cell survival and drug-resistant cells often have high levels of autophagy [39-42]. Autophagy served as a source of back-up energy that was used by tumor cells for their survival against reactive oxygen species and genomic instability induced by anticancer therapy [40, 43-46]. When we inhibited autophagy by using autophagy inhibitor 3-MA and CQ or downregulating the autophagyrelated proteins including Atg5, Atg7, and Beclin1, the protection of GSTP1 to MCF-7 cells against ADR was suppressed. These findings displayed a novel mechanism that GSTP1 protected MCF-7 cells against the cytotoxicity of ADR and resulted in the drug resistance through raising the autophagy level.

Pathways involving in autophagy have well been documented, including AMPK, PI3K-Akt, MAPK/Erk1/2, and p53/Genotoxic stress [47]. All these signaling pathways are generally targeting mTOR, a critical regulator of autophagy induction [48-50]. The PI3K-Akt-mTOR pathway plays a central role in the regulation of autophagy and blockade of autophagy via inhibiting the PI3K-Akt-mTOR pathway displays a great contribution to overcome chemotherapy resistance and resensitize the tumor cells to anticancer therapy [40, 51-53]. Our results demonstrated that GSTP1 promoted autophagy in a transferase activity independent manner, we thus conjecture that GSTP1 might act as a noncatalytic ligand-binding protein to regulate autophagy pathways. We found that GSTP1 inhibited the activation of PI3K-Akt-mTOR but not MAPK/ERK1/2 pathway. Through inhibiting PI3K-Akt-mTOR signaling, GSTP1 promoted autophagy and strengthened the resistance of MCF-7 cells to ADR. It has been reported that GSTP1 could interact with JNK, TRAF2, STAT3, etc., to regulate cellular signal transduction [16, 17, 54]. To analyze how GSTP1 regulated autophagy pathway, immunoprecipitation, MALDI-TOF, and immunofluorescence assay were conducted. These experiments confirmed that GSTP1 interacted with $110 \alpha$ subunit of PI3K, but not mTOR, AKT, and $\mathrm{p} 85 \alpha$ subunit of PI3K. PI3K are heterodimeric molecules composed of a $\mathrm{p} 85 \alpha$ regulatory subunit and a $\mathrm{p} 110 \alpha$ catalytic subunit [55]. In the presence of activating signals, the p85 subunit binds to activated RTKs, recruiting p110 to the plasma membrane, where a conformational change induced by binding relieves inhibition of p110 catalytic activity. Our finding strongly suggested that GSTP1 interacted with p110 $\alpha$ to inhibit PI3K catalytic activity.

We used Discovery Studio 4.5 software to simulate the possible domain of GSTP1 to bind with $110 \alpha$ subunit of PI3K. Results suggested that PRO123, LEU160, and ALA163 which composed a pocket in C-terminal of GSTP1 might be required. Through constructing PRO123, LEU160, and GLU163 mutation plasmids and transfecting them into MCF-7 cells, we confirmed that the C-terminal structure composed by PRO123, LEU160, and GLU163 was necessary for GSTP1 to associate with $\mathrm{p} 110 \alpha$ of PI3K and as a result, to inhibit the activation of PI3K-Akt-mTOR autophagy pathway. MDA-MB-468 is another type of human breast cancer cell line with relative low GSTP1 level. Our finding indicated that the overexpression of GSTP1 in MDA-MB-468 cells also enhanced autophagy and increased the resistance of cells to ADR suggesting the effect of GSTP1 on autophagy not only in MCF-7 but also in other breast cancer cell lines. Till now, there seems no report about GSTP1 mutation in breast cancer cells.

In conclusion, the present study demonstrated that in breast cancer cells, GSTP1 interacted with PI3K catalytic subunit $\mathrm{p} 110 \alpha$ and thereby enhanced the autophagy level induced by ADR. The pocket in C-terminal domain composed of PRO123, LEU160, and GLU163 was necessary for GSTP1 to interact with $\mathrm{p} 110 \alpha$. By this mechanism, GSTP1 protected breast cancer cells against ADR-induced cell death and increased drug resistance (Fig. 7). These new molecular insights provide an important contribution to our better understanding of the mechanism by which GSTP1 enhanced the resistance of tumor cells to chemotherapy. 


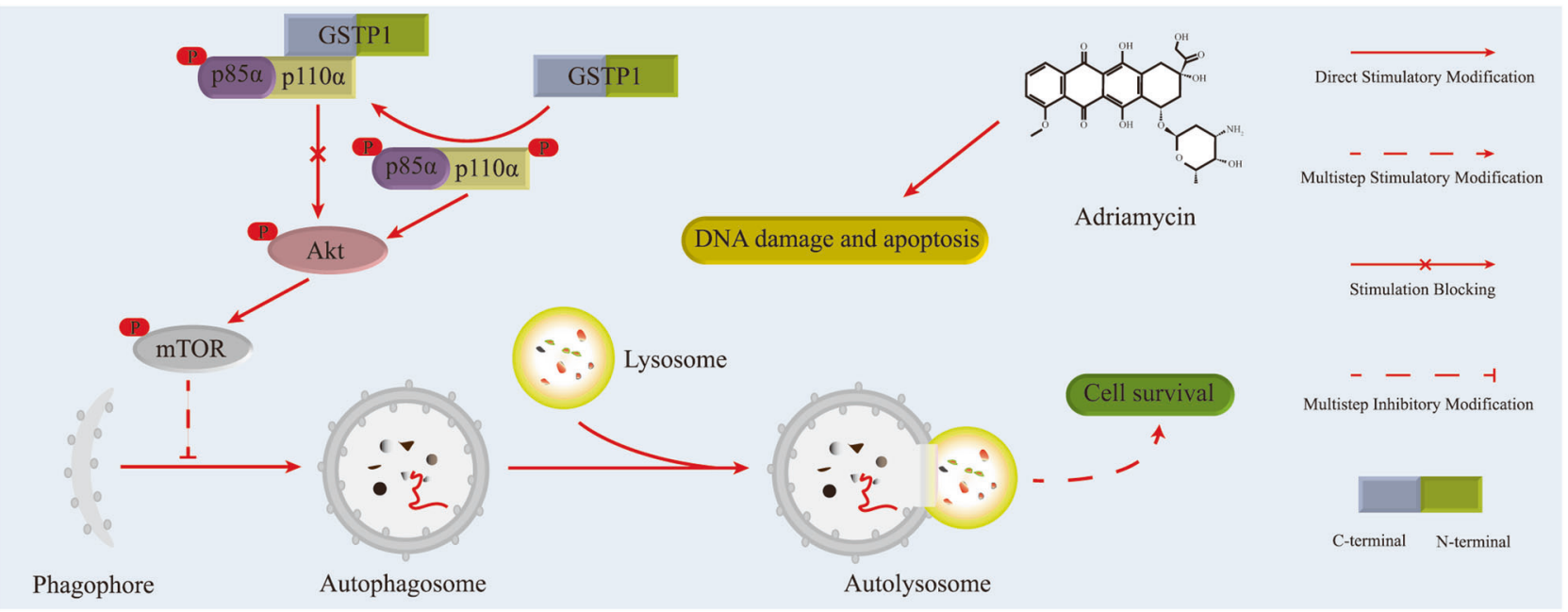

Fig. 7 Schematic representation of GSTP1 protecting breast cancer cell from adriamycin-induced cell death through promoting autophagy

Acknowledgements The authors thank Dr. Qi Wang (Nanjing Normal University, China) for kindly providing CA-AKT plasmids.

Funding This work was financially supported by grants from the Natural Science Foundation of China (Nos. 31571166 and 81771703 to L. Luo, 81471557 and 81671565 to Z. Yin, and 81602733 to Y. Yang) and the Priority Academic Program Development of Jiangsu Higher Education Institution (PADD) to Z. Yin.

\section{Compliance with ethical standards}

Conflict of interest The authors declare that they have no conflict of interest.

Publisher's note: Springer Nature remains neutral with regard to jurisdictional claims in published maps and institutional affiliations.

\section{References}

1. Geretto M, Pulliero A, Rosano C, Zhabayeva D, Bersimbaev R, Izzotti A. Resistance to cancer chemotherapeutic drugs is determined by pivotal microRNA regulators. Am J Cancer Res. 2017;7:1350-71.

2. Allen KE, Weiss GJ. Resistance may not be futile: microRNA biomarkers for chemoresistance and potential therapeutics. Mol Cancer Ther. 2010;9:3126-36.

3. Gottesman MM. Mechanisms of cancer drug resistance. Annu Rev Med. 2002;53:615-27.

4. Zheng T, Wang J, Chen X, Liu L. Role of microRNA in anticancer drug resistance. Int J Cancer. 2010;126:2-10.

5. Krishna R, Mayer LD. Multidrug resistance (MDR) in cancer. Mechanisms, reversal using modulators of MDR and the role of MDR modulators in influencing the pharmacokinetics of anticancer drugs. Eur J Pharm Sci. 2000;11:265-83.

6. Udomsinprasert R, Pongjaroenkit S, Wongsantichon J, Oakley AJ, Prapanthadara LA, Wilce MC, et al. Identification, characterization and structure of a new Delta class glutathione transferase isoenzyme. Biochem J. 2005;388:763-71.

7. Allocati N, Federici L, Masulli M, Di Ilio C. Glutathione transferases in bacteria. FEBS J. 2009;276:58-75.
8. Tew KD. Glutathione-associated enzymes in anticancer drug resistance. Cancer Res. 1994;54:4313-20.

9. Townsend DM, Shen H, Staros AL, Gaté L, Tew KD. Efficacy of a glutathione S-transferase pi-activated prodrug in platinumresistant ovarian cancer cells. Mol Cancer Ther. 2002;1:1089-95.

10. Wang AL, Tew KD. Increased glutathione-S-transferase activity in a cell line with acquired resistance to nitrogen mustards. Cancer Treat Rep. 1985;69:677-82.

11. Ciaccio PJ, Tew KD, LaCreta FP. Enzymatic conjugation of chlorambucil with glutathione by human glutathione $\mathrm{S}$ transferases and inhibition by ethacrynic acid. Biochem Pharmacol. 1991;42:1504-7.

12. Batist G, Tulpule A, Sinha BK, Katki AG, Myers CE, Cowan KH. Overexpression of a novel anionic glutathione transferase in multidrug-resistant human breast cancer cells. J Biol Chem. 1986;261:15544-9.

13. Tew KD. Redox in redux: emergent roles for glutathione S-transferase P (GSTP1) in regulation of cell signaling and S-glutathionylation. Biochem Pharmacol. 2007;73:1257-69.

14. Tew KD, Townsend DM. Regulatory functions of glutathione S-transferase P1-1 unrelated to detoxification. Drug Metab Rev. 2011;43:179-93.

15. Tew KD, Manevich Y, Grek C, Xiong Y, Uys J, Townsend DM. The role of glutathione S-transferase $\mathrm{P}$ in signaling pathways and $\mathrm{S}$ glutathionylation in cancer. Free Radic Biol Med. 2011;51:299-313.

16. Wu Y, Fan Y, Xue B, Luo L, Shen J, Zhang S, et al. Human glutathione $\mathrm{S}$-transferase P1-1 interacts with TRAF2 and regulates TRAF2-ASK1 signals. Oncogene. 2006;25:5787-800.

17. Adler V, Yin Z, Fuchs SY, Benezra M, Rosario L, Tew KD, et al. Regulation of JNK signaling by GSTP1. EMBO J. 1999;18:1321-34.

18. Townsend DM, Tew KD. The role of glutathione-S-transferase in anti-cancer drug resistance. Oncogene. 2003;22:7369-75.

19. Buchser WJ, Laskow TC, Pavlik PJ, Lin HM, Lotze MT. Cellmediated autophagy promotes cancer cell survival. Cancer Res. 2012;72:2970-9.

20. Mathew R, Karantza-Wadsworth V, White E. Role of autophagy in cancer. Nat Rev Cancer. 2007;7:961-7.

21. Mizushima N. The pleiotropic role of autophagy: from protein metabolism to bactericide. Cell Death Differ. 2005;12:1535-41.

22. Tsuchihara K, Fujii S, Esumi H. Autophagy and cancer: dynamism of the metabolism of tumor cells and tissues. Cancer Lett. 2009;278:130-8. 
23. Mizushima N, Levine B, Cuervo AM, Klionsky DJ. Autophagy fights disease through cellular self-digestion. Nature. 2008;451:1069-75.

24. Li DD, Wang LL, Deng R, Tang J, Shen Y, Guo JF, et al. The pivotal role of c-Jun NH2-terminal kinase-mediated Beclin 1 expression during anticancer agents-induced autophagy in cancer cells. Oncogene. 2009;28:886-98.

25. Oehadian A, Koide N, Hassan F, Islam S, Mori I, Yoshida T, et al. Differential expression of autophagy in Hodgkin lymphoma cells treated with various anti-cancer drugs. Acta Med Indones. 2007;39:153-6.

26. Kanzawa T, Germano IM, Komata T, Ito H, Kondo Y, Kondo S. Role of autophagy in temozolomide-induced cytotoxicity for malignant glioma cells. Cell Death Differ. 2004;11:448-57.

27. Yu M, Gou WF, Zhao S, Xiao LJ, Mao XY, Xing YN, et al. Beclin 1 expression is an independent prognostic factor for gastric carcinomas. Tumour Biol. 2013;34:1071-83.

28. Xu L, Qu XJ, Liu YP, Xu YY, Liu J, Hou KZ, et al. Protective autophagy antagonizes oxaliplatin-induced apoptosis in gastric cancer cells. Chin J Cancer. 2011;30:490-6.

29. Mizunoe Y, Sudo Y, Okita N, Hiraoka H, Mikami K, Narahara T, et al. Involvement of lysosomal dysfunction in autophagosome accumulation and early pathologies in adipose tissue of obese mice. Autophagy. 2017;13:642-53.

30. Pang J, Xiong H, Lin P, Lai L, Yang H, Liu Y, et al. Activation of miR-34a impairs autophagic flux and promotes cochlear cell death via repressing ATG9A: implications for age-related hearing loss. Cell Death Dis. 2017;8:e3079.

31. Wu YT, Tan HL, Shui G, Bauvy C, Huang Q, Wenk MR, et al. Dual role of 3-methyladenine in modulation of autophagy via different temporal patterns of inhibition on class I and III phosphoinositide 3-kinase. J Biol Chem. 2010;285:10850-61.

32. Carew JS, Nawrocki ST, Cleveland JL. Modulating autophagy for therapeutic benefit. Autophagy. 2007;3:464-7.

33. Kim YC, Guan KL. mTOR: a pharmacologic target for autophagy regulation. J Clin Invest. 2015;125:25-32.

34. Kundu M, Thompson CB. Autophagy: basic principles and relevance to disease. Annu Rev Pathol. 2008;3:427-55.

35. Miyazaki M, McCarthy JJ, Fedele MJ, Esser KA. Early activation of mTORC1 signalling in response to mechanical overload is independent of phosphoinositide 3-kinase/Akt signalling. J Physiol. 2011;589:1831-46.

36. Singh S, Okamura T, Ali-Osman F. Serine phosphorylation of glutathione S-transferase P1 (GSTP1) by PKC $\alpha$ enhances GSTP1dependent cisplatin metabolism and resistance in human glioma cells. Biochem Pharmacol. 2010;80:1343-55.

37. Zhang J, Grek C, Ye ZW, Manevich Y, Tew KD, Townsend DM. Pleiotropic functions of glutathione S-transferase P. Adv Cancer Res. 2014;122:143-75.

38. Tsou SH, Chen TM, Hsiao HT, Chen YH. A critical dose of doxorubicin is required to alter the gene expression profiles in
MCF-7 cells acquiring multidrug resistance. PLoS ONE. 2015;10: $\mathrm{e} 0116747$.

39. Mathew R, White E. Autophagy in tumorigenesis and energy metabolism: friend by day, foe by night. Curr Opin Genet Dev. 2011;21:113-9.

40. Yang ZJ, Chee CE, Huang S, Sinicrope FA. The role of autophagy in cancer: therapeutic implications. Mol Cancer Ther. 2011;10: 1533-41.

41. Chen S, Li X, Feng J, Chang Y, Wang Z, Wen A. Autophagy facilitates the Lapatinib resistance of HER2 positive breast cancer cells. Med Hypotheses. 2011;77:206-8.

42. Zou Z, Yuan Z, Zhang Q, Long Z, Chen J, Tang Z, et al. Aurora kinase a inhibition-induced autophagy triggers drug resistance in breast cancer cells. Autophagy. 2012;8:1798-810.

43. Eskelinen EL. The dual role of autophagy in cancer. Curr Opin Pharmacol. 2011;11:294-300.

44. Zhang FQ, Cheong JK. Targeting oncogene-induced autophagy: a new approach in cancer therapy? J Cancer Res. 2013;2013: 350863 .

45. Liu EY, Ryan KM. Autophagy and cancer-issues we need to digest. J Cell Sci. 2012;125:2349-58.

46. Aredia F, Scovassi AI. Manipulation of autophagy in cancer cells: an innovative strategy to fight drug resistance. Future Med Chem. 2013;5:1009-21.

47. Hippert MM, O'Toole PS, Thorburn A. Autophagy in cancer: good, bad, or both? Cancer Res. 2006;66:9349-51.

48. Sridharan S, Jain K, Basu A. Regulation of autophagy by kinases. Cancers (Basel). 2011;3:2630-54.

49. Martinez-Lopez N, Athonvarangkul D, Singh R. Autophagy and aging. Adv Exp Med Biol. 2015;847:73-87.

50. Alers S, Löffler AS, Wesselborg S, Stork B. Role of AMPKmTOR-Ulk1/2 in the regulation of autophagy: cross talk, shortcuts, and feedbacks. Mol Cell Biol. 2012;32:2-11.

51. Liu B, Wen X, Cheng Y. Survival or death: disequilibrating the oncogenic and tumor suppressive autophagy in cancer. Cell Death Dis. 2013;4:e892.

52. Chen S, Rehman SK, Zhang W, Wen A, Yao L, Zhang J. Autophagy is a therapeutic target in anticancer drug resistance. Biochim Biophys Acta. 2010;1806:220-9.

53. Sui X, Chen R, Wang Z, Huang Z, Kong N, Zhang M, et al. Autophagy and chemotherapy resistance: a promising therapeutic target for cancer treatment. Cell Death Dis. 2013;4:e838.

54. Chen D, Liu J, Rui B, Gao M, Zhao N, Sun S, et al. GSTpi protects against angiotensin II-induced proliferation and migration of vascular smooth muscle cells by preventing signal transducer and activator of transcription 3 activation. Biochim Biophys Acta. 2014; 1843:454-63.

55. Carpenter CL, Duckworth BC, Auger KR, Cohen B, Schaffhausen BS, Cantley LC. Purification and characterization of phosphoinositide 3-kinase from rat liver. J Biol Chem. 1990;265:19704-11. 